\title{
Branching Out: Establishing A Global Communication Strategy for A Foreign Branch Campus
}

\author{
Keith M. Wallace \\ Indiana Institute of Technology, USA
}

\begin{abstract}
.
Higher education institutions attempting to establish an international branch campus must create a global communication strategy in order to succeed in the short-term, long-term, and through future global crises. This article discusses best practices in updating or creating and establishing a global communication strategy for higher education institutions involved in international branch campus expansion. Global leadership communication succeeds on a macro and micro level. This article discusses eight action objectives on the macro level for the institution to incorporate in their strategy design. The eight action objectives are made up of removing organizational silence, transparency, collective reflexivity, crisis management, content management, language management, generational approach, and corporate social responsibility. On the micro level, this article discusses six important individual competencies that global leaders should possess while implementing a global communication strategy for an institution in a foreign environment. The six competencies include intercultural engagement, intercultural communication, curiosity, active listening, flexible observational lens, and a global mindset. When a branch campus is internationally established, institutional leadership needs continued development through formal learning and experiential opportunities to increase communication competencies for core global leaders. Future opportunities for organizational expatriate assignments and employee global mindset development can lay a foundation for long-term strategic success with a now globally engaged institution.
\end{abstract}

Keywords: global communication strategy, global leadership development in higher education, university foreign branch campuses, global mindset 


\title{
2nd World Conference on Teaching and Education
}

\author{
19-21 February, 2021 Vienna, AUSTRIA
}

\section{Introduction}

Higher education has been dramatically affected by the pandemic of 2020, a global crisis that left many students stranded abroad while studying and then moving to an online format amongst their domestic peers while returning home (Redden, 2020). As the institutional community witnessed in early 2020, environmental stability can change at any moment with no guarantee to return to previous operation functionality. Higher education nstitutions attempting to establish international branch campuses need to be prepared to navigate a complex status of higher education (Wilkins \& Huisman, 2012) by involving a clear communication strategy for a stable global presence in any situation. The purpose of this article is to propose best practices of establishing a global communication strategy for any institution branching into a global market of higher education.

\section{Methods}

Organizations need to understand the basic principles of global leadership communication before implementing a multifaceted strategy. Knowledge passes through differing social constructs that intend to alter behavior, motivate, and navigate via verbal and non-verbal messages (Lawrence, 2015). Global leadership communication is thus broken up into two levels, first a macro level view in which each culture is categorized by patterns of behavior and larger social and historical contexts of interculture (Martin \& Nakayama, 2011; Lawrence, 2015). Then a micro level that dives into a dyadic and context specific individual influence that makes up an entire external culture effect where interculturalists attach symbols and meaning (Kalscheuer, 2011; Lawrence, 2015). Both micro and macro levels bring importance to global leadership communication strategies as they will complement each other to make sure the organization meets the intended local adaption for success.

Without local adaptation, long-term success is jeopardized. The ability to craft skillful communication, during the branch transition, brings motivation and expressive ideas that influences organization behavior and thinking in order to succeed (Harrison \& Mulhberg, 2014). Influenced behavior reaches the emotional core of staff who then become committed to embodying the vision of the strategy of global leadership communication (Spector, 2013). To ensure differing backgrounds, languages, cultural context, and employee belief are aligned with the strategic message, global leadership communication aids the transmission to maintain innovation created by the shared belief within the single organizational goal (Matthews \& Thakkar, 2012). With the onsite organization believing in the vision, they will be ready to share it through action while aiming for long term success in the global environment.

Being in a new environment can be challenging, however, with a dedicated team the goal of the organization thrives with direct and simplistic foundations. Engraining a global communication strategy for the institution prepares the goals of the organization to be properly executed. The best practices in this article proposes eight action steps on the macro level divided into two overarching categories of internal operations and external operations that make up the global leadership communication strategy. What follows is the micro level that proposes a holistic strategic training approach for the global marketplace for short- and long-term success. 


\title{
2nd World Conference on Teaching and Education
}

\author{
19-21 February, 2021 Vienna, AUSTRIA
}

\section{Internal operations}

While branch campuses can have low success rates in international settings (Wildavsky, 2012), creating a global leadership communication strategy sets the new institutional location up to have a chance of survival. To start correctly, the institution needs to open up communication channels amongst the employees and faculty at any institution, at any time. This means removing any type of silence culture that may have happened and may still exist. Having an open discussion platform creates a community product that takes contributions from the entire organization (Deetz, 2014, January 29). If power distance exists, it needs to be lowered to fully engage conversation within the organization that retains, innovates, and lowers the communication complication within (Groysberg \& Slind, 2012). The institution needs full organizational dedication to remove silence and open up with a critical lens, which can focus on underrepresented questions, concepts, or research at a mainstream level (Collinson, 2011). With silence broken, transparency replaces the void within the communication channels.

Transparency has involved itself in the workforce with a change in generation, technology, and social norms. The importance of transparency in the modern workforce leads to an overall need for inclusivity within organizations and to employee mobility if not maintained (Whitley \& Chambers, 2009). Being transparent opens dialogue while retention builds through feedback for the new generation of workers on more levels than just a transactional role (Riklen, 2014). Building trust is a form of psychological safety within the organizational that increases engagement with employees and leaders (Spector, 2013). It is the inclusive climate that begins to build a collective and motivated mindset in the institution. To avoid faculty, staff, and leadership fixation on temporal resources, inclusion of collective reflexivity allows the organization to halt and congregate to share views on outcomes based off each one's actions in the company (Gomez \& Ballard, 2013). A practice as such allows everyone to view the mission of the institution each time and see the dependency all moving parts have within each other. This avoids being a reluctant organization who relies on momentum and past practices that can and will hinder sustainable growth, especially when the status quo is never challenged by any member of the organization (Spector, 2013). Having the ability to change when needed is important and during times of uncertainty, a vital action for survival.

The last internal action objective is crisis management and the communication that makes reduction possible. A pre-crisis simulation better prepares departments to collaborate through strong communication (Harrison \& Mulhberg, 2014). Crisis communication hinges on open communication that collaborates with truthfulness internally and externally (Ulmer, 2012). An ideal approach is appointing the right spokesperson, having preparations ready, and maintaining the transparent, trustful, and open dialogue within the company to overcome any future crisis. The strategy action objectives now must focus on the external operations.

\section{External operations}

Technology has given tools to people around the world to connect and work closer than ever. The display of information in public presence can be a publicity double-edged sword for organizations if not approached correctly. External objectives require proper content management that systematizes many organizational variables. The concept of brand 


\title{
2nd World Conference on Teaching and Education
}

\author{
19-21 February, $2021 \quad$ Vienna, AUSTRIA
}

integrity content management systems benefits the institution by having one central location (Mescan, 2004). Avoiding disorganization gives everyone in the institution the right tools to succeed. One of the most important of these tools is a language implementation strategy.

English has been described as the business language of the world, an important reason to make language an objective that is required when working with different backgrounds (Neely, 2012, May 1). Conceptualizing language under knowledge sharing benefits leadership decision making and coordination through one common language (Lauring \& Selmer, 2011). Having a language management system ensures native and non-native speakers of English interact at peak performance with each other. Each onsite culture has and continues to develop individual identities. Within the foreign environment where local cultures may feel apprehensive in learning a different language, leadership must explain that language strengthens the institutional trust both online and in person (Harrison \& Mulhberg, 2014). Younger generations may adapt quicker having grown up in a more globalized world, however, the theme of generations becomes an important action objective in this proposed strategy.

With millennials being the dominant generation in the workforce, aligning the vision building behaviors already imbedded within this generation will set up the foreign branch campuses for success (Bottomley \& Burgess, 2018). The proposed strategic plan emphasizes knowing each generation's preferred communication styles and channels with the purpose of best maximizing communication to who receives it and how best to send the messages at any time (Whitley \& Chambers, 2009). Millennials need transparency and institutions must begin focusing on communication with Generation $\mathrm{Z}$ as a long-term goal for continued operations (Riklen, 2014). Having corporate social responsibility in emerging markets relates to decision making that is ethical, legal, and beneficial to the environment and the communities which builds employees who are ambassadors of the same goals (Jayakumar, 2013). Utilizing storytelling gives meaning in a moral communication sense to the institution identity entrusted in good values (Weheimer \& Schultz, 2014). With the eight macro action objectives outlined in the internal and external settings, the micro level strategy takes equal importance.

\section{Individual level approach}

Breaking down the cultural preferences of each group, subgroup, and norms that make a leader around the world is an extremely difficult task. Each culture has their image of what makes a leader (Díaz-Sáenz, 2011), which brings the importance of a global leadership communication strategy to the micro level when possibly constructing a branch campus in a different country. There are certain competencies that a global leader must possess and these do not have to be perfected before the institution takes shape abroad, however, there needs to be opportunity for these skills to be built by all involved in the organization. A 70-20-10 percent framework can aid global leadership development, based on experiential, developmental, and formal learning (Mendenhall et al., 2017).

Intercultural engagement as a global leader is a foundation of communication competencies (Levine et al., 2007). A global leader must be able to have an interaction in a global setting because without interaction, there is limited communication and limited transfer of knowledge (Lauring \& Selmer, 2011). A related competency of engagement is an intercultural communication problem solver which bypasses different cultural backgrounds 


\section{2nd World Conference on Teaching and Education}

\section{9-21 February, $2021 \quad$ Vienna, AUSTRIA}

that hinder communication between two places or people (Kalscheuer, 2014). Achieving engagement requires interest and curiosity of global leaders when approaching new cultures and experiences.

While global leaders do not need to adopt an ethnography of communication where removing a cultural competency replaces an understanding of a new one (Hall, 2014), there does need to be curiosity for continual global development of an individual. This competency guides the learner for short-term and long-term development. Global leadership emerges from experiential interaction complemented by reflection and seeking out learning opportunities (Caputo \& Crandall, 2012). The institution can give endless opportunity for global leaders, but it is up to them and who hires them to forge the curious quest of learning.

Active listening goes along with curiosity as the global leader is open to more than their own voice in a global setting. Organizations need to listen to each other to be able to understand their point of view, global leaders need this competency to comprehend what is going on within the organization and outside (Weiming, 2014). Another competency that mirrors active listening is having a flexible observational lens, which produces a contextual leadership style built for achieving cooperation amongst different backgrounds (Aritz \& Walker, 2014). Observing and listening balance each other and make any global leader's communication skills much stronger.

The last global leader communication competency is a global mindset. A global mindset competency is viewed as the skill of someone to comprehend a new cultural environment through deep self-reflection of new emotions, new knowledge, and inspiration while reacting in the new cultural environment (Al Ariss, 2014; Javidan \& Walker, 2012). It is this competency that acts an umbrella to the other required competencies for global leaders. Developing these six required competencies is the last step in this global leader strategic communication proposal.

\section{Discussion}

Formal learning mixed with experiential and on the job development are strong approaches for increasing communication competencies with global leaders at the institution branching into a foreign market. Role playing, case studies, lectures, seminars, assessment tests, and simple real-world exposure to new cultures are ways to build global competency levels (Mendenhall et al., 2017). To minimize intercultural apprehension, a reaction that can bring uneasiness when engaging with other cultures (Neulip, 2017), starting with the talent selection is an important first step. Hiring the correct diverse candidates aids workforce communication (Lauring, 2011). The more diverse the team, the less apprehension becomes a factor in the institution aspiring to cross-culturally succeed.

Active listening improves when open dialogue happens within the organization. The collective reflexivity allows people to express their views to grasp the bigger picture (Gomez \& Ballard, 2013). For global leaders, this practice is an experiential opportunity to grow active listening skills by hearing everything there is to learn from top to bottom. Language classes are a great way for leaders to show respect and interest in intercultural communication. If English is the central language, creating conversation groups that give the non-natives an opportunity to improve their skills while natives get to learn more about their 


\section{2nd World Conference on Teaching and Education}

colleagues and feel involved can boost employee moral (Neely, 2012, May 1). Mastering technology is a smart way that global leaders can improve all aspects of intercultural communication. Like language classes, the technological skill can be shared and taught amongst different generations. Empowering younger generations, such as millennials, who "speak" certain technologies will include them in a positive way (Riklen, 2014) and strengthen colleague relationships for those who are learning from them, even if it is the global leader, now student, developing their own skills.

Developing a global mindset takes time, however, using global business travel, expatriate assignments, and even international service learning is designed to help develop global mindset (Mendenhall et al., 2017). Immersive experiences in literature, cinema, language, food, and conversation also helps build a global mindset as curiosity is driving the desire to learn and be open to new cultures. Being open also helps build the observational lens competency that aids global leaders in reading different contextual situations on the job where the understanding of different cultural contexts helps on the spot decision making (Aritz \& Walker, 2014).

\section{Conclusion}

Organizations in the global market need to develop or update a strategy based on global leadership communication (Lawrence, 2015). By focusing on best practices of eight external and internal action objectives along with placing importance on the six required global leadership competencies outlined in this proposal, branching into a different country will have the foundation of short- and long-term strategic success for higher education institutions. Developing the competencies ensures the institution will maintain success and thrive amongst a diverse faculty, staff, and student population. 


\section{2nd World Conference on Teaching and Education}

19-21 February, 2021

Vienna, AUSTRIA

\section{References}

Al Ariss, A. (2014). Global talent management. Springer Cham Heidelberg.

Aritz, J., \& Walker, R. C. (2014). Leadership styles in multicultural groups: Americans and East Asians working together. International Journal of Business Communication, 51(1), 7292. https://doi.org/10.1177/2329488413516211

Bottomley, K., \& Willie Burgess, S. (2018). Changing generations in today's workforce: Leadership skills for Millennials. Employment Relations Today, 44(4), 5-9. https://doi.org/10.1002/ert.21651

Caputo, J. S., \& Crandall, H. M. (2012). The intercultural communication cultural immersion experience: Preparing leaders for a global future. Journal of Leadership Studies, 6(1), 5863. https://doi.org/10.1002/jls.21229

Collinson, D. (2011). Critical leadership studies. In A. Bryman, D. Collinson, K. Grint, B. Jackson, \& M. Uhl-Bien (Eds.), The SAGE Handbook of Leadership (pp. 181-195). SAGE.

Deetz, S. (2014, January 29). Critical theory of communication in organizations. A first look at communication theory. https://www.youtube.com/watch? $\mathrm{v}=\mathrm{n} 4 \mathrm{R}-\mathrm{Q} 9 \mathrm{wCRIo}$

Díaz-Sáenz, H. (2011). Transformational leadership. In A. Bryman, D. Collinson, K. Grint, B. Jackson, \& M. Uhl-Bien (Eds.), The SAGE Handbook of Leadership (pp. 299-311). Sage.

Gómez, L. F., \& Ballard, D. I. (2013). Communication for the long term: information allocation and collective reflexivity as dynamic capabilities. The Journal of Business Communication, 50(2), 208-220. http://doi.org/10.1177/0021943612474992

Groysberg, B., \& Slind, M. (2012). Leadership is a conversation. Harvard Business Review, 90(6), 76-84. https://hbr.org/2012/06/leadership-is-a-conversation

Hall, B.J. (2014). Theories of culture and communication. In Asante, M., K., Miike, Y., \& Yin, J. (Eds.). (2014). The Global intercultural communication reader (2nd ed.). Taylor \& Francis.

Harrison, B. \& Mulhberg, J. (2014). Leadership communications: How leaders communicate and how communicators lead in today's global enterprise. Business Expert Press

Javidan, M., \& Walker, J. L. (2012). A whole new global mindset for leadership. People and Strategy, 35(2), 36. https://www.hrps.org/

Jayakumar, T. (2013). CSR communication in emerging economies: Need for a new paradigm: A case study of a multinational and an Indian transnational's CSR communication in India. International Journal of Business Insights \& Transformation, 6(2). https://www.ijbit.org/

Kalscheuer, B. (2014). Encounters in the third space. Links between intercultural communication theories and postcolonial approaches. In Asante, M., K., Miike, Y., \& Yin, J. (Eds.). (2014). The Global intercultural communication reader (2nd ed.). Taylor \& Francis. 


\section{2nd World Conference on Teaching and Education}

19-21 February, 2021

Vienna, AUSTRIA

Lauring, J. (2011). Intercultural organizational communication: The social organizing of interaction in international encounters. Journal of Business Communication, 48(3), 231255. https://doi.org/10.1177/0021943611406500

Lauring, J., \& Selmer, J. (2011). Multicultural organizations: Common language, knowledge sharing and performance. Personnel Review, 40(3), 324-343. https://doi.org/10.1108/00483481111118649

Lawrence, T. (2015). Global leadership communication: A strategic proposal. Creighton Journal of Interdisciplinary Leadership, 1(1), 51. https://doi.org/10.17062/cjil.v1i1.8

Levine, T. R., Park, H. S., \& Kim, R. K. (2007). Some conceptual and theoretical challenges for cross-cultural communication research in the 21st century. Journal of Intercultural Communication Research, 36(3), 205-221. http://doi.org/10.1080/17475750701737140

Matthews, C., L., \& Thakkar, B. (2012). The impact of globalization on cross-cultural communication. In H. Cuadra-Montiel (Ed.), Globalization-education and management agendas. InTech. https://doi.org/10.5772/45816

Martin, J.N. \& Nakayama, T.K. (2014). Thinking dialetically about culture and communication. In Asante, M., K., Miike, Y., \& Yin, J. (Eds.). (2014). The Global intercultural communication reader (2nd ed.). Taylor \& Francis.

Mendenhall, M.E., Osland, J.S., Bird, A., Oddou, G.R., Stevens, M.J., \& Maznevski, M.L.,\& Stahl, G.K. (2017). Global leadership: Research, practice and development (3rd ed.). Routledge.

Mescan, S. (2004). Why content management should be part of every organization's global strategy: to meet the challenges of creating, using, and sharing content in a global marketplace, organizations should consider a content management system. Information Management Journal, 38(4), 54-58. https://go.gale.com/

Neeley, T. (2012, May 1). Why everyone at your company should speak (a little) English. https://hbr.org/video/2226849428001/why-everyone-at-your-company-should-speak-alittle-english

Neuliep, J. W. (2017). Intercultural communication apprehension. The International Encyclopedia of Intercultural Communication, 1-5. https://doi.org/10.1002/9781118783665.ieicc0045

Redden, E (2020). International and study abroad students see major disruptions. Inside Higher Ed. https://www.insidehighered.com/news/2020/03/20/covid-19-disruptsinternational-student-exchange-both-directions

Riklen, L.S. (2014). Where they're coming from. Understanding the millennial mind-set is the first step to creating a productive environment for the workers of the future. Communication world, 15-17. https://www.iabc.com/

Spector, B. (2013). Implementing organizational change: Theory into practice (3rd ed.). Prentice. 


\section{2nd World Conference on Teaching and Education}

Ulmer, R. R. (2012). Increasing the Impact of Thought Leadership in Crisis Communication. Management Communication Quarterly, 26(4), 523-542. https://doi.org/10.1177/0893318912461907

Wehmeier, S. \& Schultz, F. (2014). Communication and corporate social responsibility. A storytelling perspective. In Ihlen, O., Bartlett, J.L., \& May, S. (2014). The handbook of communication and corporate social responsibility, 468-488. Wiley Blackwell.

Weiming, T. (2014). The context of dialogue. In Asante, M., K., Miike, Y., \& Yin, J. (Eds.). (2014). The Global intercultural communication reader (2nd ed.). Taylor \& Francis.

Whitley, L. T., \& Chambers, B. T. (2009). Strategic communications in a complex world: How senior executives successfully plan and communicate in global enterprises. International Journal of Coaching Organizations, 7(2), 6-18. http://www.ijco.info/

Wildavsky, B. (2012). The great brain race: How global universities are reshaping the world. Princeton University Press.

Wilkins, S., \& Huisman, J. (2012). The international branch campus as transnational strategy in higher education. Higher education, 64(5), 627-645. http://doi.org/10.1007/s10734-0129516-5 